\title{
(t)
}

\section{DE ABESS A ABEPSS: CRISE, TRANSIÇÃO E CONQUISTAS}

From Abess to Abepss: crisis, transition and achiements

\section{Reinaldo Nobre Pontes ${ }^{1}$}

Para Nobuco Kameyama

O presente texto objetiva apresentar o processo desenvolvido na última gestão da Associação Brasileira de Ensino de Serviço Social $\left(\right.$ Abess) ${ }^{2}$ - nessa denominação - (dezembro/1997-dezembro/1998), fundada em 1946 e modificada em 1998, quando em Assembleia Geral Extraordinária, passou a denominar-se Associação Brasileira de Ensino e Pesquisa de Serviço Social (Abepss). Essa foi uma gestão de transição (de apenas um ano, quando o previsto estatutariamente são 2 anos) escolhida principalmente para criar e aprovar um novo Estatuto para entidade, que favorecesse a superação de seus antigos entraves administrativos e financeiros, e também aprovar junto ao Ministério da Educação (MEC) as novas Diretrizes Curriculares e avançar na discussão junto às escolas de Serviço Social.

\footnotetext{
1 Presidente da Abess, gestão 1997-1998 e Vice-presidente Norte da Abess, gestão 1995-1997. Mestre em Serviço Social (PUC-SP); Doutor em Sociologia (UCM-Espanha); Professor Adjunto da UFPa/ PPGSS. E-mail: <rpontes@ufpa.br>

${ }^{2}$ Essa gestão esteve composta pela seguinte equipe: Diretoria executiva: Reinaldo Nobre Pontes - Presidente (Unama), Adriana Fonseca de Azevedo - Secretária (Ufpa); Zoraide Leitão de Oliveira Tesoreira (Unama); Aglair Alencar Setubal - Vice-presidente Norte (UFPI); Silvana Mara Moraes Santos (UFRN); Ivanete Salete Bosquette Ferreira (UNB); Marina Barbosa Pinto Vice-presidente Leste (UFF); Eliveti Cecília de Andrade - Vice-presidente Sul 1 (Unisul); Marlene Merisse - Vice-presidente Sul 2 (Unitau). Diretoria do Cedepss: Myrtes Aguiar de Macedo (PUC-RJ); Nobuco Kameyama (UFRJ); Suely Bulhões da Silva (PUC-RJ); Conselho Consultivo: Denise Bontempo Birche de Carvalho (UnB); Franci Gomes Cardoso (Ufma) e Raquel Tolosa Jorge (Unesp/Franca).
} 
Apresentamos o texto em três movimentos: inicialmente, partimos do Contexto, descrevendo sumariamente o panorama da realidade no período da gestão, além dos desafios postos à entidade; em seguida, em A gestão 97/98, apresentamos os projetos desenvolvidos no referido período e os resultados alcançados; por fim, em Curta caminhada, longa jornada, analisamos as lições apreendidas no processo e o legado dessa gestão.

\section{CONTEXTO}

O final da década de 1990 apresentou-se como um momento de importantes mudanças na realidade brasileira. Em nível mundial, estávamos vivendo um momento especial da crise do capital - inaugurada com a ruptura do ciclo virtuoso do welfare state, no início dos anos 70 - que deu lugar à era neoliberal, ou era da globalização excludente (THERBORN, 2001), que, por sua vez, pleiteou: a reestruturação produtiva (passagem do fordismo ao toyotismo; a acumulação flexível); o predomínio e liberdade do capital financeiro; a reestruturação do trabalho (desregulamentação do trabalho, fragilização do salariato); a redução do Estado (redução dos direitos e políticas sociais), para ficar nos principais (ANTUNES, 2008; BRAVERMAN, 1987). Tais fatores afiguravam-se como mecanismos articulados que visavam à retomada do desenvolvimento capitalista (isto é, aumento do crescimento econômico, do emprego e do consumo). Os vinte anos da aplicação dessas estratégias testemunharam o crescimento da pobreza, da desigualdade social, do desemprego, da fome e da desproteção social (ANDERSON, 1995).

No Brasil, então situado na periferia desse processo, estávamos em plena era Fernando Henrique Cardoso (FHC) (1995-2002), que colocava em marcha um projeto de governo afinado com as estratégias acima mencionadas, corporificadas na política de estabilização monetária, nas privatizações, na abertura dos mercados nacionais, na transferência para sociedade civil de responsabilidades estatais da proteção social. Nesse último campo, diferenciávamo-nos dos países centrais, cujos sistemas de proteção social se achavam mais desenvolvidos pela incipiência dos sistemas protetivos e baixa ca- 
pacidade de financiamento das políticas públicas (PONTES, 2007).

No final da década de 1990, os efeitos distributivos do Plano Real (1995) já haviam cessado, ou seja, a pequena redução no número de pobres e a elevação da renda familiar dos mesmos voltaram aos patamares de antes do plano de estabilização. Registre-se que, nos dois últimos anos da década de 1990, sob os impactos da crise financeira mundial, o governo opta pela estratégia recessiva, levando ao aumento do desemprego, da pobreza e da desigualdade Social (GONÇALVES, 1999).

No campo do ensino superior, o Governo FHC adotou visivelmente os paradigmas preconizados pelo Banco Mundial, de abertura para o mercado, redução do financiamento público, favorecendo a tendência de privatização progressiva e focalização nas demandas de mercado, aligeirando a formação profissional (WANDERLEY, 1998).

Nesse sentido, o governo propõe uma ação de reforma curricular em todas as áreas, com base na aprovação da Lei de Diretrizes e Bases da Educação (LDB) (Lei nº 9394, de 20/12/1996), segundo a qual uma das primeiras tarefas das Instituições de Ensino Superior (IES) brasileiras foi a de apresentar a definição das diretrizes curriculares para os cursos de graduação, em substituição aos antigos currículos mínimos - tarefa essa que no caso do Serviço Social coube Abess, que não esperou o sinal oficial para responder a essa necessidade, já que desde 1993, muito antes da aprovação da nova legislação, tal organização já vinha atuando junto às escolas de Serviço Social³ (JORGE, 1998).

Foi nesse cenário socioeconômico e político-acadêmico acima sumariado que a gestão dezembro 97/dezembro 98 se processou tendo como um claro desafio resistir ao cenário de aligeiramento na formação profissional e de redução nos financiamentos para pesquisa e pós-graduação.

3 Ver a série Cadernos Abess, $\mathrm{n}^{\circ} 1$ a 8, Editora Cortez. 


\section{A GESTÃO 1997-1998}

Na XXX Convenção da Abess/Cedepss realizada em Recife, em dezembro de 1997, a gestão (1995-1997) que ali se encerrava - sob a competente e compromissada liderança de Marieta Koike, da qual tive a satisfação de participar na condição de Vice-Presidente da Região Norte - tinha muita clareza de duas questões cruciais sobre a instituição Abess/Cedepss: 1. a referida gestão conseguiu de forma democrática construir uma proposta de Diretrizes Curriculares avançada, no entanto, precisava de muito investimento junto às unidades de ensino para se concretizar; 2 . a forma institucional em que se apresentava a entidade era insustentável administrativa e financeiramente, além de ter se tornado evidente a necessidade de uma reforma estatutária que lograsse superar esse entrave e também a antiga polarização entre ensino de graduação e pesquisa/pós-graduação.

Diante desse quadro, a Assembleia Geral ocorrida durante a Convenção acima referida deliberou que a gestão Abess/Cedepss 97/98 seria de transição, com uma programática específica: reestruturação institucional: construção de um novo estatuto com a criação de uma entidade única, extinguindo o Cedepss; aprovação das Diretrizes Curriculares da área junto ao MEC e favorecimento da construção dos novos Currículos Plenos dos cursos de Serviço Social no Brasil. Na área de atuação do Cedepss, as ações prioritárias foram: discussão das mudanças na política de Pós-Graduação e Pesquisa - Coordenação de Aperfeiçoamento de Pessoal de Nível Superior/ Conselho Nacional de Desenvolvimento Científico e Tecnológico (Capes/CNPq), com ênfase nos novos critérios de avaliação dos Programas de Pós-Graduação; atualização do mapeamento das pesquisas na área de Serviço Social; organização e realização do VI Encontro Nacional de Pesquisadores em Serviço Social (Enpess).

Como se pode notar, a agenda básica proposta à nova gestão era extensa e complexa, considerando especialmente que se destinava a uma gestão de apenas um ano. Contudo, graças à coesão do grupo que dela se encarregou, da fidelidade aos compromissos ao Projeto ético-político do Serviço Social, essa gestão não só cumpriu 
essa apertada agenda, mas também aditou novas metas e projetos, honrando-os, quais sejam: rearticulação internacional; modernização administrativa e das comunicações da entidade; dinamização da articulação com as escolas de Serviço Social; participação na organização e realização do XIX Congresso Brasileiro de Assistência Social (CBAS)4.

\subsection{0 novo estatuto}

Considerando o contexto acima esboçado, e seus consequentes desafios, podia-se verificar que para fazer face à magnitude da missão histórico-institucional enfeixada na Abess, havia um flagrante descompasso entre os necessários encaminhamentos e enfrentamentos com que a entidade teria que avançar nos campos do ensino de graduação e pós-graduação, bem como nas áreas de pesquisa e extensão e em sua estrutura jurídica, política e econômica, cujo enfrentamento tornou-se inadiável.

A alteração da pauta normativa de uma entidade com a história da Abess/Abepss precisava manter coerência política e metodológica com a tradição de construção coletiva e democrática da nova entidade, razão pela qual manteve a dinâmica de construção através de Oficinas (locais, regionais e nacional). A diretoria executiva, para facilitar o processo de revisão estatutária, construiu uma proposta prévia com assessoria jurídica especializada (sem ônus para a Abess), com base nas conclusões da XXX Convenção da Abess/Cedepss, e enviou para todas as unidades de ensino e Programas de Pós-Graduação em Serviço Social para debate e encaminhamento de sugestões. No âmbito das escolas de Serviço Social, foram realizadas oficias em todas as regionais entre agosto/outubro através das quais se levaram críticas, propostas e sugestões para o novo Estatuto. No âmbito da Pós-Graduação, a proposta foi debatida por ocasião da reunião do Fórum de Pós-Graduação em Serviço So-

\footnotetext{
${ }^{4}$ A necessidade de atender a esses desafios assumidos pela gestão em um espaço reduzido de tempo, associado à contumaz inadimplência de muitas escolas filiadas, pressionou a gestão financeira da entidade a um superávit reduzido ao final da gestão.
} 
cial, em maio/1998, na UFRJ, cujo produto foi um documento síntese (Abess/Fórum), por sua vez, apresentado à deliberação superior da Assembleia Geral, em dezembro de 1998, na Universidade de Brasília, sendo o novo estatuto da entidade ${ }^{5}$ aprovado por unanimidade, concluindo democraticamente o processo de mudança institucional ${ }^{6}$.

As principais mudanças ${ }^{7}$ trazidas pela nova carta normativa da instituição foram as seguintes:

- alteração do nome da entidade, que passou a se chamar Associação Brasileira de Ensino e Pesquisa em Serviço Social (Abepss), extinguindo o Cedepss e integrando, na mesma entidade, a tríade ensino (graduação e pós-graduação), pesquisa e extensão;

- as unidades de ensino que compõem o conjunto de sócios institucionais passam a ser: curso de graduação e programas de pós-graduação em Serviço Social;

- ampliação da base de sócios com a criação da categoria de sócios individuais: professores, assistentes sociais (supervisores e pesquisadores) e estudantes (graduação e pós-graduação);

- inclusão na estrutura da Diretoria Executiva Nacional e das Diretorias Regionais dos cargos de Coordenador Nacional de Graduação e Coordenador Nacional de Pós-Graduação; Criação do Conselho Fiscal da entidade.

\subsection{Aprovação e implantação das diretrizes curriculares}

Do ponto de vista das finalidades da Abess/Cedepss, esse eixo programático foi o principal balizador de nossa gestão. Tal relevância se compreende recordando-se que o documento Diretrizes Gerais

\footnotetext{
5 O estatuto com as alterações ocorridas até a presente data se encontra disponível no site da Abepss, a saber: Disponível em: <http://www.abepss.org.br/briefing/documentos/estatuto.pdf>.

${ }^{6}$ Registre-se que, nas gestões que se seguiram, esse estatuto aprovado foi ampliado e aperfeiçoado. 7 As mudanças aqui relatadas se restringem àquelas deliberadas pela Assembleia Geral de 1998, já que outras alterações foram realizadas no período de 1999-2011.
} 
para o curso de Serviço Social ${ }^{8}$ (ABESS; CEDEPSS, 1996), ainda não havia recebido a aprovação final na Secretaria de Ensino Superior do Ministério da Educação (Sesu/MEC) e carecia ainda de conhecimento mais aprofundado, debates na direção da construção dos currículos e projetos pedagógicos em cada unidade de ensino de Serviço Social. Competiu a nossa gestão enfrentar esses dois importantes desafios.

Do ponto de vista das finalidades da Abess/Cedepss, esse eixo programático foi o principal balizador de nossa gestão. Compreendendo que a partir do documento construído pela gestão anterior (1995/1997): Diretrizes Gerais para o curso de Serviço Social (ABESS; (EDEPSS, 1996), resultante de um amplo movimento envolvendo as 72 Escolas de Serviço Social brasileiras entre 1994-1996 e que concluiu a revisão do Currículo Mínimo vigente na formação profissional desde 1982. No entanto, esse documento ainda não havia recebido a aprovação final na Secretaria de Ensino Superior do Ministério da Educação (Sesu/MEC) e carecia ainda de conhecimento mais aprofundado, debates na direção da construção dos currículos e projetos pedagógicos em cada unidade de ensino de Serviço Social. Competiu a nossa gestão enfrentar esses dois importantes desafios.

Em relação ao primeiro, realizaram-se várias gestões junto ao Sesu/ MEC e à Comissão de Especialistas para a aprovação da proposta Abess/Cedepss na íntegra. Houve a necessidade de introduzir ajustes na proposta original - a pedido da Comissão de especialistas (Sesu/MEC) -, os quais foram realizados pela Diretoria Executiva e por consultores da Abess/Cedepss. Esse processo de aprovação somente pôde ser concluído na gestão seguinte.

No entanto, o necessário debate e aprofundamento das Diretrizes visando a subsidiar as unidades de ensino Serviço Social (filiadas ou não à entidade) ocorreu através da realização de oficinas em todas as regionais da entidade, o que garantiu a continuidade do processo inaugurado em 1993.

\footnotetext{
${ }^{8}$ Construído pela gestão anterior (1995-1997), resultante de um amplo movimento envolvendo as 72 Escolas de Serviço Social brasileiras entre 1994-1996 e que concluiu a revisão do Currículo Mínimo vigente na formação profissional desde 1982.
} 
A publicação de $n^{\circ} 8$, dos Cadernos Abess, última da série com apoio da Editora Cortez, fez parte das ações desse eixo estratégico, trazendo conteúdos voltados ao entendimento do processo de formação profissional, num contexto de reforma universitária, e ao processo de construção dos projetos pedagógicos, diante das novas diretrizes curriculares e experiências significativas de propostas curriculares. Essa foi a principal publicação da gestão (CADERNOS..., 1998).

O projeto de capacitação profissional e docente, idealizado desde a gestão anterior, mas lançado na nossa gestão - sob a forma de Programa de Capacitação Continuada em para Assistentes Sociais: Curso de Especialização em Serviço Social e Política Social, em parceria com CFESS, Cead/UnB -, constituiu-se em uma estratégia acadêmico-política de fortalecimento da fundamentação teórico-metodológica, tanto dos profissionais quanto dos docentes em todo o país. Verificava-se, naquele momento, uma importante demanda reprimida para curso de pós-graduação, haja vista a baixa oferta de cursos nesse nível nas universidades públicas e os altos custos nas escolas privadas. A oferta desse curso a preço de custo alcançou um número recorde de inscritos e concluintes. Os textos contidos nos cinco volumes dos módulos, dada sua qualidade e objetividade, alcançaram um público bem maior do que os inscritos nesse Programa de Capacitação continuada, e hoje figuram na bibliografia de todos os cursos de Serviço Social, atestando o êxito da estratégia de capacitação continuada no sentido de impulsionar a implantação das novas diretrizes curriculares, e em última análise nutrir as bases do Projeto ético-político da profissão.

\subsection{Pesquisa e Pós-graduação: CEDEPSS em transição}

No que tange à área de pesquisa e pós-graduação, alguns desafios se impuseram a nossa gestão: as mudanças na política de pós-graduação e pesquisa dos órgãos de fomento Capes e CNPq, com ênfase nos novos critérios de avaliação dos programas; a necessidade de atualização do mapeamento da pesquisa na área de Serviço Social; a separação entre os níveis de graduação e pós-graduação e de ensino, extensão e pesquisa. 
Diante desse quadro, a direção do Cedepss verificou a necessidade de criar ações no sentido de responder a esses desafios. A primeira delas foi reunir o Fórum de pós-graduação em Serviço Social (integrado pelos coordenadores dos cursos de mestrado e de doutorado em Serviço Social), o que aconteceu duas vezes em nossa gestão e produziu os seguintes resultados: elaboração do projeto da nova revista científica da entidade (aprovado na Assembleia Geral extraordinária (novembro/1996); elaboração e divulgação de documento sobre a trajetória da pós-graduação em Serviço Social no país, divulgado no VI Enpess; elaboração da proposta do Fórum para revisão estatutária da Abess, apresentada por ocasião da citada Assembleia Geral. Além dessas importantes ações, o Cedepss ainda realizou o IV Enpess, participou da organização do IX CBAS e colaborou decisivamente para o novo formato institucional.

Merece destaque a realização do IV Enpess, o último evento promovido por essa gestão, que ocorreu apesar de o CNPq haver suspendido concessão do auxílio financeiro prometido. A decisão de realização do evento sustentou-se no entendimento de criar resistência à política governamental de cortes de recursos às atividades de pesquisa e também de manter a continuidade dos eventos anuais de pesquisadores da área de Serviço Social. Obstáculos não impediram o êxito do evento, que inscreveu 161 comunicações de pesquisa, revelando não apenas o interesse dos pesquisadores em intercambiar conhecimentos, mas também a capacidade política de resistir às adversidades e concretizar ações.

Coerentemente com a programática acadêmico-política, essa gestão ainda realizou concomitantemente ao projeto-eixo da entidade as seguintes ações complementares:

- Rearticulação internacional9: Filiação da entidade à Internacional Asociation of Schools of Social Work (IASSW); Participação no Congresso mundial e Assembleia Geral dessa entidade (Jerusalém/1998); Participação no Congresso Latino Americano de Tra-

\footnotetext{
${ }_{9}^{9}$ Naquele momento, percebemos um descompasso entre a maturidade do Serviço Social brasileiro e sua representatividade nas entidades mundiais e regionais. Âmbito latino-americano e internacional era necessário.
} 
balho Social e Assembleia Geral da Associação Latino Americana de Trabalho Social (Alaets) (Santiago/1998); Conferência no Congresso Nacional do Uruguai (Montevideo/1998); Reunião com representante do Colegiado de Serviço Social da Itália (Roma/1998);

- Qualificação na administração e comunicações: criação do primeiro site da entidade e endereço eletrônico; publicação de duas edições do Jornal In Formação (circulação nacional); utilização de telerreuniões para reuniões da diretoria e início do recadastramento das escolas de Serviço Social; regularização da entidade perante a Receita Federal e no Siscaf.

Essas ações complementares expressam o alcance político da nossa gestão, porque buscou o fortalecimento da condição de ator político no âmbito do Serviço Social (nacional e internacionalmente) e fora dele.

\section{CURTA CAMINHADA, LONGA JORNADA...}

A gestão 1997-1998 representou uma continuidade na construção do chamado Projeto Ético-Político do Serviço Social, que, desde o emblemático Congresso da virada, vem construindo por dentro da trincheira de uma profissão - inserida no contexto sócio-histórico brasileiro - ações em direção à transformação da realidade brasileira. O âmbito da formação profissional, da pesquisa científica e da prática institucional nas políticas públicas é fértil campo para o debate dos projetos sociais em confronto e também para a luta na hegemonização do projeto de emancipação social.

A partir dessa compreensão, organizou-se o grupo que dirigiu a Abess/Cedepss em tal gestão - que, a propósito, tive a honra de liderar nesse breve período - o qual, por seu turno, mostrou-se coeso nos princípios, respeitoso nas diferenças e corajoso nos desafios. $\mathrm{O}$ resultado alcançado nos projetos desenvolvidos fala por si mesmo.

Das muitas lições desse processo, destaco principalmente: a importância das articulações internas e externas à categoria profissio- 
nal: com CFESS, Enesso e muitas universidades públicas e privadas (destaque para UFPA, Unama, PUC-RJ, UnB e UFRJ); importância da potencialização do processo sociopolítico de Oficinas (local, regional e nacional) no processo de construção das decisões e da maturação das Diretrizes Curriculares; a necessidade de valorização das condições objetivas de um ator político (Abess/Cedepss) a empreender sua reforma institucional e sua lenta processualidade intrínseca.

O legado de nossa gestão pode ser resumido na aprovação do novo estatuto, na publicação dos Cadernos Abess, n 8 (CADERNOS..., 1998) na rearticulação internacional e na realização do VI Enpess.

\section{REFERÊNCIAS}

ABEPSS; CEDEPSS. Proposta básica para o Projeto de Formação Profissional. Revista Serviço Social \& Sociedade, São Paulo, n. 50, 1996.

. Relatório de gestão Abess/Cedepss: gestão 97-98. Belém, 1999. Mimeo.

ANDERSON, P. Balanço do neoliberalismo. In: GENTILI, P.; SADER, E. (Org.). Pós-neoliberalismo: as políticas sociais e o Estado democrático. Rio de Janeiro: Paz e Terra, 1995.

ANTUNES, R. As formas contemporâneas de trabalho e a desconstrução de direitos sociais. In: SILVA, O.; YASBEK, C. (Org.). Políticas públicas de trabalho e renda no Brasil. São Paulo: Cortez, 2008.

BRAVERMAN, H. Trabalho e capital monopolista: a degradação do trabalho no século XX. Rio de Janeiro: Guanabara, 1987.

CADERNOS ABESS. São Paulo: Cortez, n. 8, 1998.

GONÇALVES, R. Distribuição de riqueza e renda: alternativas para a crise brasileira. In: LESBAUPIN, I. (Org.). O desmonte da nação: balanço do governo FHC. 3. ed. Petrópolis: Vozes, 1999. 
JORGE, M. R. T. A construção curricular no ensino de Serviço Social. Cadernos Abess, São Paulo, n. 8, 1998.

PONTES, R. N. Pobreza y ciudadanía: la dialéctica de los conceptos em las políticas contra la pobreza (Brasil 1995-2002). 2007. 404 p. Tese (Doutorado em Sociologia) - Universidad Complutense de Madrid, Madrid, 2007.

THERBOR, G. Dimensões da globalização e a dinâmica das (des) igualdades. In: GENTILE, P. Globalização excludente. Petrópolis: Rio de Janeiro, 2001.

WANDERLEY, M. B. Formação profissional no contexto da reforma do sistema educacional. Cadernos Abess, São Paulo, n. 8, 1998. 